\title{
Women and Men in Traditional and Modern Organisations Psycho-Sociological Research
}

Popescu Silvia

\author{
Economics Faculty " Titu Maiorescu" University, Faculty of Management and Business, University of \\ Bucharest, Romania
}

\begin{abstract}
The gender and racial composition of the Romania workforce is rapidly changing. As more women enter the workforce and as they enter jobs that have traditionally been dominated by men, issues related to sex and gender in work settings become increasingly important and complex. Research addressing sex and gender in the workplace is conducted in several distinct disciplines, ranging from psychology and sociology to management and economics. The goal of this paper is to communicate a variety of social- psychological research on gender issues that affect work behaviors to upper level undergraduate and graduate students in applied psychology and business. Furthermore, it can serve as a centerpiece in a topics course devoted to gender in the workplace that might be offered within the curriculum of I/O, vocational psychology, or management,. The major and fundamental purpose of the present research was to optimize organizational performance resulting from the application of diversity management. To achieve the strategic goals mentioned were set a series of objectives among which we mention in particular the following objectives:
\end{abstract}

- Was to identify the opinions of both managers and employees on women and men in work related situations and in instances that could influence organizational decision making.

- Moreover, aspects that would supply more information on the recruitment, promotion and management processes / practices regarding sexual harassment and working hours were also under scrutiny.

Keywords: leadership styles, gender differences, managerial abilities, androgynous orientation.

\section{Introduction}

One goal of this paper is to cover a range of issues that both women and men encounter in the workplace but that are not commonly explored in any depth in management or work psychology textbooks. We hope to expand the conceptualization of "human" in HRM to include both women and men. We believe that gender and sex issues have important implications for work-related and HRM issues. Unfortunately, discussions of work often refer (explicitly or implicitly) to workers as men. Therefore, any discussion of another group of workers (in this case women) is at risk of being dismissed as a specialty book (about women). However, this paper is not simply about women at work. This is a paper about people interacting with each other in the context of work organizations. Our discussion includes literature that reveals similarities and differences between men and women at work and, wherever possible, among men and women of color and of varying socioeconomic status. We hope to identify what we know about employed men and

Copyright (C) 2012 Popescu Silvia. This is an open access article distributed under the Creative Commons Attribution License unported 3.0, which permits unrestricted use, distribution, and reproduction in any medium, provided that original work is properly cited. Contact author: Popescu Silvia E-mail: silvipopescu@gmail.com 
women as well as what we do not know concerning gender and important work and organizational problems.

\section{General Information on the Survey:}

- The research was performed in private and state-owned companies in Romania (Bucharest as well as the rest of the country);

- The three types of questionnaires used:

+ Questionnaires for managers

Questionnaires for employees

4 Questionnaires for human resources managers

- The survey was completed on a representative sample for the workplace in Romania, in the months of October, November and December 2011, i.e.

- 656 employees and 358 managers from 65 private and state owned organisations have answered the query.

- Three types of questionnaires were conceived and customized: one for employees, one for managers and one for human resources managers.

- Among the employees, 300 of the respondents were women and 356 men, while among the managers, 155 respondents were women and 203 men.

- For some of the organisations, the human resources manager or the personnel inspector filled in an organizational file - in all 35 such query files were collected.

- Two focus groups targeted at employed women of ages 25 to 40, both highly and medially educated, were performed.

- Other 2 focus groups had as subjects employed men, of ages 25 to 40 , medium to high education.

- The questionnaire structured on the issues stated above was interpreted and led to a series of conclusions which we present in the topics order:

\section{The Main Research Domains:}

- Time spent at work / working hours

- Evaluation and promotion

- Opinions on professions, tasks and orientation in the workplace

- Management styles and methods

\section{Literature Review}

For excellent reviews of the literature on the devaluation of women's competence see Lott, 1992 and Heilman, 2001 Investigations of the evaluation of male and female performance in equivalent situations have frequently found that males tended to be rated more favourably than females when the presented evidence is identical. When presented with information on the performance of a male or female painter (Pheterson et al., 1971) or applicants for an overseas study programme (Deaux and Taynor, 1973), male performance is rated more favourably than female Research in the 1970s showed that men and women are stereotyped and evaluated differently (Dipboye et al. 1975, 1977; Fidell, 1970, Goldberg,1968; Gutek and Stevens, 1979; Haefner, 1977; Rosen and Jerdee, 1974; Schein, 1975 and Terborg and Ilgen, 1975) Females are often evaluated less favourably than males. For people to perceive a woman as more competent than a man, they must be given explicit evidence of the woman's clear and substantial superiority (Shackelford et al., 1996). As a result of the sex stereotyping influence, women are often evaluated as less acceptable candidates for stimulating, challenging jobs (Taylor and Ilgen, 1981) and not perceived as having the necessary attributes for success in high status positions within their organizations (Heilman, 1984). When judging by the standard set by men, women frequently fail to measure up (Forrest, 1989). Sex role stereotyping continues to have a substantial impact on human resource management decision (Heilman, 1980, 
1984; Heilman and Saruwatri, 1979; McKenna and Johnson (1981) show that females are discriminated against in a female- oriented occupation in the presence of high selection risk. Kanter (1977) has argued that many of the negative traits ascribed to women managers may be a product of the deadend roles they occupy. than those of male articles, regardless of the sexual association of the professional field. However, using Goldberg's original stimulus materials, or comparable ones, several investigators have been unable to find significant sex-ofauthor effects (Chobot et al., 1974; Gross and Geffner, 1980; Levenson et al., 1975; Panek et al., 1976). The research on women and how they are rated produces very mixed results. There is evidence to support Goldberg (e.g. Cline et al., 1977). There is evidence showing bias against women, even in the skill with which they shelve library books (Schmitt and Lappin, 1980). Despite this and other evidence of the bias against women, a substantial number of studies have found no differences in rating men and women (Heilman and Guzzo, 1978; London and Stumpf, 1983). Some have found that higher evaluations are given to women (Bigoness, 1976; Hamner et al., 1974; Norton, et al., 1977). Wallston and O'Leary (1981: 19) were able to conclude that, although a number of studies have not found real differences in the level of competence exhibited by women and men in specific positions, differences are perceived to exist'. Women continue to be evaluated with respect to her competence based in part on dress and appearance and wearing appropriate dress makes women feel more role confident (Bartlett, 1994; Guy and Banim, 2000). A person's view of their attributes will vary according to their position in the organizational power hierarchy (Fagenson, 1990; Kanter, 1977). Those occupying positions at the upper corporate levels have power and are in an advantageous position.

Poor evaluations of women employees in appraisal may be helping perpetuate lack of equal opportunities (Wilson and Beaton, 1992). A study by Alban-Metcalfe and West (1991) (see also Alban-Metcalfe, 1987) has shown how women perceive themselves as more likely to show their feelings, more sociable, and more intellectual (which is not surprising if they were better academically qualified) than did men. The need for power has been shown to be closely linked with managerial success (Kotter, 1977; McClelland and Burnham, 1976). Research by Kanter (1977) has contradicted this assumption that women have lower power needs and that women would not be interested in positions of increased responsibility and influence. She found that decreased interest in responsibility and influence were functions of status power differences in organizational employment rather than a function of gender.

\section{Paper Content}

\section{Time Spent at Work / Working Hours}

Key aspects which help us analyze the survey's data.

- A good time management implies the efficient performance of tasks within a specified timeframe, keeping control over daily activities at work. It leads to increased performances and allows for a good organisation in the long run.

- The work of employees, either women or men, who do overtime for long periods of time loses in performance compared to employees working within similar conditions but sticking to regular working hours.

- Employees who strike balance between job hours and leisure work most efficiently.

- An employee is more productive (works better), if there is an equilibrium between his or her private and professional life.

- Balance is given by the duration (how long) and the quality (how) of the time spent in the workplace and outside it (with family etc.). 
- When the employee spends too much time at work and / or when being at work is preoccupied with personal or family related issues, then he or she is out of balance(called "conflict between work and family life").The same desequilibrium is present when the employee is considering work related issues off working hours or when with family.

The consequences of this state of imbalance:

\section{A) On the employee}
a) Emotional issues (stress, depression etc.),
b) Physical issues (fatigue, burnout, headaches etc.) and
c) Social issues (isolation, difficulties in relating etc.)

B) On the organisation / company:

a) Decrease in productivity,

b) Increase in absenteeism,

c) Increase in presenteeism / face time (time spent at work not actually working),

d) Procrastination,

e) Increase in break time length and frequency etc.;

C) On the family:

a) Conflicts with family members,

b) Flawed communication within the family

\section{Conclusion:}

An employee, either male or female, spending too much time at work will gradually become less effective and less efficitent.

The data of the survey substantiate:
A) That many employees / managers, both women and men:

$\checkmark \quad$ Frequently do overtime.

$\checkmark \quad$ Do so due to a flawed management of time, tasks and department coordination.

$\checkmark \quad$ Experience difficulties in taking time off to solve private or family issues.

B) That many employees:

$\checkmark$ Are encouraged by the management to work beyond regular office hours, doing overtime being frequently taken into consideration in employee evaluation and promotion.

$\checkmark$ Accumulate frustrations because they are required to do unpaid overtime.

$\checkmark \quad$ Think of family / personal issues when at work.

$\checkmark$ Think out work issues when with family or in their spare time.

C) ...And that:

$\checkmark \quad$ There are no significant differences between male and female employee behavior as far as time usage at and off work is concerned.

At least one man out of 4 and one woman out of 6 work overtime daily.

At the question:

How frequently do you work overtime?

The answers of the respondents reveal that:

Men work overtime more than women.

The fact that men do overtime more than women is influenced by the opinions on the family responsibilities of women / men: „People consider a man does not have that many family responsibilities compared to a woman and can thus do overtime or 
respond to any request outside working hours. While she needs to come home." (employee opinion, focus-group).

Expectations are that more men than women do overtime.

Men are thought of as having fewer responsibilities in the family life than women. The latter are required to strive for balance between career and family time. With men, the pressure is off radars.

Overtime can sometimes translate as travel. As per the employees' focus groups, Women are thought of as less available for travel than men, especially when they "also have families", "and then one naturally prefers a man, one thinks he will have the time".

The human managers' perspective: overtime "looks good" -an indicator in employee evaluation and a criterion for promotion. Staying overtime is seen by the interviewed managers (especially the young ones) as a way to press employees to make efforts for the targeted productivity. Some managers define employee involvement as "support granted to colleagues, participation in team building activities or availability to work overtime if needed." (Opinion of a human resources manager, interviews)

From another perspective, some human resources managers (interviews) state that the availability to work overtime is taken into consideration:

\section{For Pay Raises:}

"Work done (quantity and quality of work, irespect of history with company), commitment to the company, family issues. Overtime is necessary." (opinion of a human resources manager, interviews)

"We generally take into consideration professional performance; we take into consideration the availability to do overtime in certain cases." (Opinion of a human resources manager, interviews)

\section{For Employee Evaluation:}

"Performances and the commitment to the company, ideas that can bring profit to the enterprise, the person's capacity to help out outside regular office hours". (Opinion of a human resources manager, interviews).

Overloading the schedule is tolerated by the representatives of the state authorities who are complacent with the assurances from the management on the paid leaves for the worked Saturdays and Sundays. (Opinions employees, focus-groups)

The employees' perspective is as follows: uncompensated, overtime can easily become a source of frustration and conflict. Employees (as per the focus-groups) correlate the discontent generated by going beyond the regular 8 working hours with the inequity resulting from both the fact that not everyone is doing overtime, and, on the other hand, the absence of the salary advantage for those who do.

Why is, most often overtime needed?

Less than any other reason, employees do overtime because they receive additional tasks, because they are minutely attentive to details, because they depend on the work of another colleague or because, they have too many responsibilities for the position they occupy ("too big a hat"). Over $65 \%$ of the questioned employees indicate emergencies as the main reason for doing overtime.

At least one employee out of 2 works overtime because of an emergency. Only $6,60 \%$ of those who do are in such a situation because they have too many responsibilities beyond their job description.

At the question

How frequently do you work overtime?

The answers of the respondent managers have shown that: 
Almost one manager in 2 does overtime daily. Almost $75 \%$ of the managers do overtime daily or at least 2-3 times per week.

At the question

\section{What is the main reason you do overtime?}

The answers reveal that:

Over $50 \%$ of the managers consider that an employee who works overtime is more appreciated by the management.

At the question

Do you or do you not agree with the statement:"An employee who works overtime is more appreciated by the management."?

From the answers we can infer that: Over $50 \%$ of the managers have difficulties in taking $1-2$ hours off to handle family issues.

Managers, to a greater extent than employees, declare that they have difficulties in taking hours off to handle family issues in an usual working month.

At the question

In a usual month, how difficult is it to take 1 - 2 hours off work to handle family issues?

From the answers we can see that:

There are little differences between women and men as far as the difficulty in taking time off to handle family issues is concerned. The data is presented through the rapport of women and men to the total of those who declare a certain amount of difficulty in taking hours off to handle personal issues.

At the question

How frequently does it happen that when at work, you would think of certain family or personal issues?

The answers of the questioned show that:
Differences between women and men are insignificant as far as the frequency of thinking of private matters while at work is concerned.

$28 \%$ of women and $23,31 \%$ of men think of private matters frequently during working hours, and almost $61 \%$ of men and $56 \%$ of women rarely think of private issues.

At the question

To what extent do you think that providing working hours related incentives for employees with children is necessary for the employees and efficient for the company?

From the managers' answers we can conclude that

Over $60 \%$ of the managers consider that providing working hours incentives (different opening and closing hours, reduced number of hours, different times and lengths for meal breaks etc.) is necessary for the employees.

$40 \%$ of the managers consider these measures useful for them and for the company / organisation.

Regarding the incentives / schedules of employees with children, some human resources managers consider that:

They are useful because: valuable human resource are retained; less money is spent on new employees recruitment and training; people in the organisation are more motivated and more loyal as a consequence;

But that

- They cannot be in place because they require financial, material and human resources that organisations do not have (reference is made to kindergartens for the employees' children);

While others consider that:

- They are not efficient for the company / organisations they cause imbalances such as: 
- Problems arise as a result of the employee's absence from work;

- If the employee starts the working hours earlier than his or her manager, his or her work cannot be evaluated / appraised;

- This kind of working hours are encouraged and more and more employees will desire to adopt it.

\section{Evaluation and Promotion}

How are employees promoted and evaluated? Who ends up being promoted? How are employees being appraised?

How are we to interpret the data?

Key aspects that help us analyze the research data.

- A correct promotion decision is the one based on the high employee performance, that is on his or her good work results.

- To offer relevant information for promotion, the employee performance is to be correctly appraised, against indicators such as number and quality of tasks fulfilled, communication style with colleagues / superiors on relevant aspects regarding work situations, management of activities and work relations etc.

- Ambiguity of promotion and evaluation processes fosters employee discrimination. The lack of objective performance indicators leads the management into making promotion decisions based on their own perceptions on performance, which could be gender construed, that is the perception of the work of men could be different from that of women.

- The attitudes and opinions on women and men competencies.

The data in this survey show that:

- Less than half of the managers consider that "good work results" represents one of the top 3 factors accountable for their respective promotion and which determines the promotion of a certain employee in the company / organisation where he or she works.

- The appraisal of the employee's performances is done on less standardized procedures and criteria.

- Most of the employees and managers consider that women are faced with more barriers in their careers and that men are preferred for leadership positions.

Only $47 \%$ of the managers consider "good work results" represents one of the top 3 factors that determine the promotion of a certain employee in the company / organisation.

Managers consider that the desire of the employees to get involved in problem solving in the workplace is the second factor that determines the promotion of an employee (over $48 \%$ of the managers as opposed to only $16 \%$ of the employees mentioned this factor in the top 3 factors accountable for a promotion).

\section{Employee Perceptions on Employment and Promotion Criteria}

\section{Employment and Promotion Based on Competence versus Recommendations.}

Employees consider that rarely is a well paid job secured on competence criteria.

"The recommendation" counts the most and also stands for the other processes, such as: promotion from within, employee motivation, salary negotiations. Less paid employees are firmly convinced and frustrated that a well paid position is unobtainable in the absence of high or influent relations or money.

Contrariwise, those working in multinationals are convinced by the accuracy of the permanent corporate exams and appraisals, the most important criterion in accessing a good position and preserving it being their professional skills; 
they do however admit that sometimes recommendations help, particularly when they come from someone already employed within the company (focus groups). Also, the dominant opinion is that, in the private sector, employment is more frequently done on competence than in the state owned sector.

\section{Promotion Models}

A great deal of the employees are not aware of promotion models, clear criteria made known from the moment of employment in the organisation. The most difficult situations occur in the case of employees of medium education active in very small enterprises, where the promotion could be a whim of the manager and takes, as a matter of fact, the form of a bonus (most times a relatively modest amount of money for which the employee is required to work well beyond his or her powers). This kind of bonification acts like a boomerang on the employee's efficiency, as he or she most often prefers not to make the effort.

"The more capable you are, the more obstacles are raised in your path." "You must play the fool in order to..." (Employee opinions, focus-groups).

The higher educated employees in state owned enterprises or in privately owned Romanian enterprises seem to carry on with the same pattern and not enjoy more creative or more structured bonuses. The general impression is that "there is no incentive when a certain problem has been solved, for instance when a case has been handled and closed, where the beneficiary is the employer. There is absolutely no motivation to preserve good behavior, nothing is awarded irespect of the actions taken, and one sees one's colleagues earning twice one's pay and it kind of brings one down."

The only cases when we can talk of a relatively coherent promotion system is with the multinationals, where there is an employee performance monitoring and evaluation in place, based not only on subjective impressions, as is the case with most local enterprises.

Perceptions of managers and human
resources managers on criteria for
employment and promotion are based on
Performance evaluation systems for
promotion

A very small number of the reviewed companies evaluate employee performance based on valid human resources instruments. The general impression is that this chapter of human resources processes is treated at most times superficially, considered easy to handle with internal means, that is based on intuition.

"Performances and the commitment to the company, ideas that could bring profit to the company, the person's capacity to help beyond regular working hours".

A person that is committed to the company does not necessarily work overtime; bud does have ideas that benefit the company.

\section{Promotion Criteria}

When talking about promotion, the managers (interviews) firstly take into consideration the involvement and the efficiency. Employee involvement is understood either as an adequate behavior with customers / clients or as a commitment to the workplace and belonging to the staff.

Efficiency is particularly appreciated by older managers or those in corporations with a longer history on the market. The involvement is considered essential for evaluation by the younger managers, or those in corporations that have recently entered the market. As far as promotion is concerned, very few companies can assert how long the decision making process will take. In smaller companies promotion is not an option and in the medium to large companies, promotions are made circumstantially.

The promotion for top and middlemanagement is addressed in such terms as follows: „Do we have someone from 
within?" The person in the immediately inferior position is recommended by the direct superiors. The promotion decision is generally taken within a month." (Interviews managers)

Human resources managers consider that, generally, large corporations evaluate personnel periodically, on 3 criteria:

- Percentage of accomplishment in given tasks;

- Execution quality;

- Attachment / commitment to the company - job involvement / participation.

\section{Perceptions of Personnel Services Suppliers/Human Resources Consultants on Employment and Promotion Criteria.}

The perspective on promotion criteria in the companies that are consulted by the subjects of the interviews does not differ much from what managers think on promotion. Very few could give concrete examples of more effective ways of evaluating employee performance. Either way, a combination between performance criteria and the employee's personal profile could be, in some's opinion, the best solution for a performant management. It is up to each person's communication resources („personal charisma, capacity to network"). There are also evaluation systems based on figures. More and more companies resort to performance and have performance evalaution systems, management by objectives etc.Another criterion would be ther traditional one, seniority in the company. I would not believe that it is still formally in use; however, informally, senitority and experience in the company are clearly connected to performance. It is assumed that "the longer an employee goes back with the company, the more competent, the more able and more knowledgeable..." Promotion is also done in many companies based on professional performances, but it is not a basic criterion. The personal profile is more important than profesionalism. For instance, when promoting someone to a leadership position, what is relevant is not his or her accomplishments, but the psychological profile (he or she must be accepted and wished by the team). In the case of promotions to management / leadership positions, what it is very important is the candidate's personal profile, i.e. acceptable traits of character, desirability from the would be managed / lead team's point of view (interviews with suppliers of personnel services).

The personnel services suppliers / human resources consultants (interviews) remind us of two performance evaluation styles:

1. Based on modern systems (i.e. according to management by objectives);

\section{Traditional.}

"It is assumed that the longer an employee has been with the company, the more experienced he or she is, the more able, and more knowledgeable..." (opinion of supplier of personnel services).

A small number of human resources managers (interviews with human resources managers) believe that employee performance evaluation is based on elaborated, scientific techniques. They do however opine that in practice, the informal procedures, based on intuition, are more frequently in use: „Performances, plus commitment to the company, ideas that can benefit the company, one's capacity to help out within and beyond office hours".

$49 \%$ of the organisations included in the survey declare that they do not possess employee performance evaluation systems. At the question:

Are there in your company employee performance evaluation systems?

From the answers we can conclude that:

$51 \%$ Yes $49 \%$ No

In more than half of the organisations that declare they do possess employee 
performance evaluation systems, the task is handled within individual discussions.

At the question:

What is the modality whereby employee performance evaluation is carried out in your company?

The answers show that:

There are no significant method differences in employee work evaluation based on the gender of the direct rapport (the coordinating superior). Both men and women managers mainly evaluate their employees through "the analysis of their work". In most cases, the general opinion is that, during the promotion process, differences are perceived between women and men. Men can be promoted to superior ranks easier than women, despite the latter being considered more attentive and preoccupied with their professional background. Men tend to be associated with the qualities that go with leadership and management concepts. Women, on the other hand, are seen as having more difficulties in being promoted. Most human resources managers observe that there are less successful women than men, and that it is accepted as reality and goes unanalyzed, it is seen as preordained, as something that occurs without any possible intervention to induce change. Human resources consultants resolve that more men in charge than women is an act of chance, happenstance. In several domains, experienced promotable individuals tend to be men. That in Romania, generally, the woman is less seen as a top manager could be, in some's view, a model that is hard to part with.

"There probably is also a social model whereby the woman is not seen as a business person. In our country things may have taken place slower. But there are many successful women in high places. I am assuming that before 1989 this parti-pris was more pregnant, and those that learned how to do business after the revolution were men because they already had better positions, in the leadership".
The employees consider that the promotion of a woman is done slower than a man's, and that it generally hides a sacrifice. (Focus-groups)

„People think that men do not have that many obligations as women and they can do overtime or answer to any request after hours. While women are needed at home." "If a woman is supposed to work for 8 hours, after those 8 hours she will need to go grocery shopping, has a kid to take to school, a parent meeting to attend at school, or other issues. At home it is not the man that keeps shop with the cleaning and meal preparation. Men rarely do."

Employees' opinions on women promotions are, still, also determined by the level of frustrations accumulated in the workplace. Consequently, the bigger the workplace frustration, the more women promotion is coldly considered. Most times, the arguments are pertaining to injustices met in the workplace. Some of the higher educated men in this category consider that women promote easier, and, in their view, "unjustly" so. The others are under the impression that women promote harder than men because family takes up more of the time they could allot to professional development.

"They have something else, a smile, they know how to get under your skin."

"Women promote easier than men, in my opinion."

"Well, there are many jobs that require availability for travel. And a woman is less available for travel once she also has a family. And than it is normal to prefer a man, you would think he will have the time."

"I have colleagues that graduated from the Polytechnical Institute, have been hired as engineers, while most girls that graduated from the same Polytechnical Institute have started with secretarial positions." (employees opinions, focus groups).

From the answers offered at the question: 
In your opinion, generally, who meets more obstacles in career development?

Addressed to managers, we can see that:

Over $68 \%$ of the managers and supervisors consider that women meet more obstacles in career development than men.

From the answers offered at the question: In your opinion, which are the main obstacles in the professional evolution of an employee?

We can see that:

More than half of the employees consider that promotion to leadership positions on subjective criteria represent one of the 3 obstacles in the professional evolution of an employee.

From the answers offered at the question:

In our opinion, will a woman candidating to a leadership position be required more information and will she be evaluated more attentively than a man applying for the same position?

\section{Addressed to managers, we can infer that:}

More than 2 out of 5 managers consider that a women candidating to a leadership position will be required more information and will be evaluated more attentively than a man applying for the same position.

Almost twice more women than men consider that a woman candidating toa leadership position will be required more information and will be evaluated more attentively than a man applying for the same position.

From the answers offered at the question:

What is the main reason a woman candidate is evaluated more minutely?

We can see that:

A body of opinions, transformed into prejudice that leads to discrimination constitutes the factors that determine a more minute evaluation of women candidating for the same position as men.

From the answers offered at the question:

In your opinion, to work as top management, who is more preferred, women or men?

We can observe that:

Over $49 \%$ of the managers and $59 \%$ of the employees consider that men are preferred for top management positions. Almost half of the women consider that men are preferred for a company's top management.

From the answers offered at the question: Do you or do you not agree with the statement "A woman employee with children will be less inclined to do overtime than other employees"?

We can observe that:

Over $75 \%$ of the managers consider that a woman employee with children will be less inclined to do overtime than other employees.

These data should be correlated with the following: almost 1 in 2 managers does overtime daily and over $58 \%$ of the managers consider that employees who do overtime are more appreciated by the management.

From the answers offered at the question:

In general, do managers tend to employ good communicators?

We can observe that:

$98 \%$ of the managers consider that managers tend to employ good communicators.

\section{Values over Behaviours}

Opinions on women and men who become barriers in optimal / correct decision making regarding employment and promotion at work. 


\section{Key Aspects that Help Analyzing the Survey Data}

Out of the desire to preserve and enhance a positive organisational image, there is the tendency to declare and promote certain values, although they are not to be found in the management or staff behavior. The values of an organisation are not the declared ones, though. The values are those that are to be found in daily behaviors and that are encouraged through various behaviours / actions. There are many situations where the inclination for certain values is declared, but not matched with behaviors and are not supported / encouraged through behaviours / actions at the organisational level.

Example: In a certain organisation, such values as taking on "responsibility” and „initiative” are asserted. The manager however, decides every time, in minute details, what the employees are to execute. In this organisation, values are not real, only stated. And so because the manager, through his or her behaviour, does not offer the employees the possibility to take the initiative and to exert responsibility in their task accomplishment. Moreover, he or she does not support employees in developing their capacities to initiate and take responsibility regarding various tasks. In establishing the real values of an organisation, the first step is identifying the behaviours that define each value. There are then two options to measure them: observing daily behaviours and identifying opinions related to these behaviours. An example of an opinion regarding responsibility and initiative, which shows that these values are not "real" is the manager's assertion that,employees do not have the capacity to perceive the organisation's problems and to identify solutions for them."

Identifying the opinions is an important element, since most times people make decisions and react according to their opinions and convictions. In this survey, with reference to the value called "gender equality / equal gender opportunity" a series of managers' opinions on women and men were measured, in work situations and situations that could influence organisational decision making.

Data in the survey reveal that:

Many managers:

- Consider men to be better executives, faster paced, thinking more than women on ways to generate profit.

- Consider that, most times, professions such as public relations, accounting are preferred by women, and the technical and management are preferred by men.

\section{Many Employees Consider that:}

- Men are more inclined to make decisions and take risks, while women have better relations with their colleagues and develop employee competencies.

- Generally, managers tend to employ good communicators.

- Men are better business managers than women.

- Men are motivated by competition to a greater extent than women.

- Generally, men are better managers / executives than women.

- Women employees with children will be less inclined to do overtime.

- Men in particular are inclined to consider ways to generate bigger profits.

- Men react more rapidly than women in extreme situations / a crisis.

- An employee who puts in overtime is more appreciated by the management. Twice as many men than women consider that men react faster than women in extreme situations / a crisis.

11 employees out of 100 consider that men ought to be employed rather than women when fewer jobs are available. 
Most managers (89\%) consider that most times, professions regarding public relations, human resources, accounting are preferred by women, while the technical and the management are preferred by men.

At the question:

In your opinion, are women managers or man managers more oriented towards ...?

$\checkmark$ Making a profit.

$\checkmark$ Developing employee competencies.

Developing good work relationships with their colleagues and bosses.

$\checkmark$ Making decisions and taking on risks.

One manager in 4 considers that mostly women managers are more oriented towards developing good work relationships with their colleagues and bosses.

One manager in 5 considers that mostly women managers are more oriented towards developing employee competencies.

When asked:

In your opinion, are women managers or man managers more oriented towards making decisions and taking on risks?

Almost one man out of 3 considers that men managers are more oriented towards making decisions and taking on risks.

When asked:

In your opinion, are women managers or man managers more oriented towards developing employee competencies?

More than one woman in 5 consider that women managers are more oriented towards developing employee competencies.

\section{The Woman and Multiple Roles}

The woman is seen in the context of the need to balance two important roles: the one at home, within the family, and the one at work. Most respondents consider a woman's success at work as complementary to familial success. That would be reason there are so few successful business women, as they are required to divide their time between these two occupations.

"The successful woman is not the one with a bright career but the one that has succeeded in doing good work both professionally and personally, where personal means family, children, home, friends, social status. It is natural that a woman should allow for time these things to the detriment of the career..."

„A woman, in addition to work, also has a home, and a home means cleaning, washing, ironing, cooking, everything; I would say that this is the reason she does not have time to do many other things".

Women opinions versus men opinions qualities that guarantee securing good employment.

In the opinion of men, these qualities are:

Education, qualifications;

$\checkmark$ Recommendations from previous employers;

$\checkmark$ Applicants aspect;

Money or relations / networking.

"You must have your back covered, have money, have the right person, have somebody tell you where to go. Otherwise, no pay, no entry. Stay out... "

"Professional experience. I sent a lot of emails on e-jobs (career website) and have received the replies that my resume was reviewed, but I have never been contacted by any company. They are not interested by experience."

"They are not interested in the person and we end up at influential affiliations / relations. They make the offers just to get 
covered, but those to be employed are known way before that."

Women think that in order to secure good employment the following are required:

Age under 40;

$\checkmark$ Experience-qualifications, education;

Pleasant looks.

"The problem is different in Romania, in my opinion. Women over 40, quite many of them, do not meet the competency criteria required for any position. And those who do, come with salary requirements that the employer will not meet, preferring to employ someone with less experience, but less paid. And this is where the fracture occurs. Not only for women, but for anyone over 40-45. Just as well, there are exceptions I have met, people over 45, competent and not that pretentious, good workers, employees, well received in the workplace."

"Here I disagree with you, as I think that over 30 one has more experience, knowledge and competencies, everything it takes."

\section{Methods and Styles of Management}

Key aspects that help us analyze the survey data.

A very important element in efficient employee performance management is positive feedback transmitted from the manager to the coordinated employee.

On one hand, positive feedback shows the employee what he or she has done well, motivates him or her to continue to do so in the future, improves the relationship between the employer and the employee.

On the other hand, punishment as management method is inefficient. Punishment does not help the employee solve the problem, as it does not teach him or her what is to be done in place of the undesired behaviour, and moreover, it deteriorates the relationship between the manager and the managed. Managers consider that most of them sanction employees verbally when the latter have failed in fulfilling a task.

$70 \%$ of the employees declare that their boss supports them in improving their work performance.

$10 \%$ more managers working in companies run by a woman than in companies where the CEO is a man declares that they have good relations with the management.

There are no noticeable differences in the way women and men managers communicate with their staff regarding their work.

\section{Women in Management and Valuable Partnerships}

The successes of women are explained over good partnerships. A woman is successful if she has the support of either a man, or the family. (Focus group emplyees). In the opinion of the participants to the focus groups, men have careers easier and in most cases, independently. Very few voices in the group of higher educated men attribute the success of a man to a strong woman behind him.

\section{Women Managers and Risk}

For women managers, success implies accepting risk, that not being a typical female behaviour. Women rather self position themselves around "familial" values such as stability and safety.

"Women are more content with a smaller business, but more stable and safer, while men are more willing to take on risks and be more noticed, if successful."

„Women do not have the courage to take risks. By their own nature they need stability and safety and starting a business takes risks. I'd rather my family were well and have my own home with a monthly pay than risk to be a millionaire and lose everything... the man immediately takes it all from the beginning". (Employees opinions, focus groups)

Building on the answers received, we offer 


\section{Solutions in Case Change is Desired in the Organization}

\section{Encouraging behaviors that correct stereotypes:}

a. Women and men apply for positions considered typical for the other gender

b. Colleagues and superiors support the employee found in a typical situation for the other gender

c. Women negotiate expectations the superior has when they fill in positions considered typically masculine

d. Women managers faced with resistance from their staff are given support

2. Establishing clear criteria to monitor performance and for promotion

3. Identification of leadership abilities in women / men

4. Allotment of a visible project in the company to a woman manager

5. Development of a mentorship programs for the new executives

6. Management development skills programs for women

7. Creation of managers networks communities, both women and

\section{Conclusions and Implications}

Throughout the research we identify important human resource issues and topics that have not traditionally been treated as mainstream topics in industrial and organizational (I/O) psychology or HRM. Among the topics that have historically been perceived (and sometimes dismissed) as women's issues, yet are now increasingly of concern to both male and female HRM and I/O professionals, are sexual harassment, child-care and childbearing issues, career progress, and stress and health. We believe the entrance of increasing numbers of women into the workforce renders these issues important to men, women, and organizations.

Recommendations on measures resolution / decreasing the problem Suggested alternative contexts using skills and positive influence skills of women and men.

\section{What Can you do as an Employee / Employees}

- Identify and affirm your own skills and competencies that you recommended for a position of leadership and how you can harness these skills and competencies, also identified additional resources that you need on entry into such a position;

- Check your own attitudes about gender differences in leadership and find alternative ways of thinking;

- Identify their distorted expectations and find as much information confirm / deny these expectations to test their validity;

- Provide concrete information management as often as their own performance;

- Decisions taken will be based on objective data rather not unrelated to performance judgments. Request feedback from the manager's permanent;

- Seek necessary conditions for achieving a management job in terms of resources, support, job structure, work and travel program, as close to the time of entry into such a position,

\section{What Can You Do as a Manager:}

- Check their attitudes about gender differences in leadership and find alternative ways of thinking in these situations;

- Subordinated support people who occupy a position of management, especially in the initial period of that appointment. Your support means to specify clearly the expectations, resource 
allocation, decision-making authority to provide continuous feedback of these people, willingness to negotiate job requirements;

- Encourage negotiation of terms and expectations of the appointment of a person in a position of management;

- Encourage daily practice those behaviors that exploit gender differences within the team;

- Collect as much information about the performance of subordinate managers, male or female, which realy decisions about its performance. Create as many situations its behavior observation and feedback about the performance of permanent.etc.

\section{What Can You Do as a Manager of Human Resources:}

- Establish clear criteria for recruitment, promotion to leadership positions, to be transmitted / known to employees;

- Establish objective standards for assessing the comparative job, so the comparison may not appear by default (with examples from his own experience of the employee);

- Formulate a procedure for promotion be based on objective criteria base don performance;

- Build career plans and experience range from potential employees, allocation of projects aimed at the direction of these plans;

- Use instruments to identify skills that each person be actions based allocation of human resources in the organization;

- Management training on methods of decision-making performance;

- Introduce a balancing professional and personal life to allow access of women in top management positions.

\section{Acknowledgment}

This work was supported by the strategic grant POSDRU/89/1.5/S/62259, Project "Applied social, human and political sciences. Postdoctoral training and postdoctoral felowship in social, human, and political sciences" cofinanced by the European Social Fund within the Sectorial Operational Program Human Resources Development 2007-2013.

\section{References}

Alban-Metcalfe, B. (1987). "Male and Female Managers: An Analysis of Biographical and Self-Concept Data," Work And Stress1(3), 207-219.

Alban-Metcalfe, B. \& West, M. (1991). 'Women Managers,' Chapter 12 in J. Firth Cozens and M. West, (Eds), Women at Work, Open University Press, Milton Keynes.

Bartlett, K. (1994). 'Only Girls Wear Barrettes: Dress and Appearance Standards, Community Norms and Workplace Equity,' Michigan Law Review, 9, 2541-2582.

Condry, J. \& Dyer, S. (1976). "Fear of Success: Attribution of Cause to the Victim," Journal of Social Issues 32, 63-83.

Deaux, K. \& Lewis, L. L. (1984). "Structure of Gender Stereotypes: Interrelationships among Components and Gender Labels," Journal of Personality and Social Psychology, 46, 991-1004.

Deaux, K. \& Taynor, J. (1973). "Evaluation of Male and Female Ability: Bias Works Two Ways," Psychological Reports, 32, 261262.

Dipboye, R. L., Arvey, R. B. \& Terpstra, D. E. (1977). "Sex and Physical Attractiveness of Raters and Applicants and Determinants of Resume Evaluations," Journal of Applied Psychology, 62, 288-294.

Dipboye, R. L., Fromkin, H. L. \& Wiback, J. K. (1975). "Relative Importance of Applicant Sex, Attractiveness and Scholastic Standing 
in Evaluation of Job Applicant Resources," Journal of Applied Psychology, 60, 39-43.

Dodge, K. A., Gilroy, F. D. \& Fenzel, L. M. (1995). "Requisite Management Characteristics Revisited: Two Decades Later," Journal of Social Behavior and Personality, 10, 6, 253- 264.

Fagenson, E. A. (1990). "Perceived Masculine and Feminine Attributes Examined as a Function of Individual's Sex and Level in the Organizational Power Hierarchy: A Test of Four Theoretical Perspectives," Journal of Applied Psychology, 75(2), 204-211.

Fidell, L. S. (1970). "Empirical Verification of Sex Discrimination in Hiring Practice in Psychology," American Psychologist, 25, 1094-1098.

Forrest, A. (1989). "Women in a Man's World," Journal of Management Development, 6, 61- 68.

Goldberg, P. (1967). 'Misogyny and the College Girl,' Paper Presented at the Meeting of the Eastern Psychological Association, Boston, April,1967.

Goldberg, P. (1968). "Are Women Prejudiced Against Women?," Transaction, 5, 28-30.

Goodwin, M. H. (1990). He-Said-She-Said: Talk as Social Organization among, Black Children, Indiana University Press, Quoted in Tannen.

Gross, M. M. \& Geffner, R. A. (1980). "Are the Times Changing? An Analysis of SexRole Prejudice," Sex Roles, 6, 713-722.

Gutek, B. A. \& Stevens, D. A. (1979). "Effects of Sex of Subject, Sex of Stimulus Cue and Androgyny Level on Evaluations in Work Situations Which Evoke Sex Role Stereotypes," Journal of Vocational Behaviour, 14, 23-32.

Guy, A. \& Banim, M. (2000). "Personal Collections: Women's Clothing Use and Identity," Journal of Gender Studies, 9, 3, 313-327.
Haefner, J. E. (1977). "Sources of Discrimination among Employees: A Survey Investigation," Journal of Applied Psychology, 62, 265-270.

Heilman, M. E. (2001). "Description and Prescription: How Gender Stereotypes Prevent Women's Ascent up the Organizational Ladder," Journal of Social Issues, 57, 4, 657-674.

Heilman, M. E. \& Saruwatri, L. R. (1979). "When Beauty Is Beastly: The Effects of Appearance and Sex on Evaluations of Job Applicants for Managerial and Non Managerial Jobsm" Organizational Behaviour and Human Performance, 23, 360-372.

Heilman, M. E. \& Stopeck, M. H. (1985a). "Being Attractive: Advantage or Disadvantage? Performance Based Evaluations and Recommended Personnel Actions as a Function of Appearance, Sex And Job Type," Organizational Behaviour and Human Decision Processes, 35, 202-215.

Heilman, M. E. \& Stopeck, M. H. (1985b). "Attractiveness and Corporate Success: Different Causal Attributions for Males and Females," Journal of Applied Psychology, $70(2), 379-388$.

Kanter, R. M. (1976). 'Why Bosses Turn Bitchy,' Psychology Today, May, 56-59, 8891.

Kanter, R. M. (1977). Men and Women of the Corporation, Basic Books, New York.

Kotter, J. P. (1977). "Power, Dependence and Effective Management," Harvard Business Review, 55, 125-136.

Levenson, H., Burford, B., Bonno, B. \& Davis, L. (1975). "Are Women Still Prejudiced Against Women? A Replication and Extension of Goldberg's Study," Journal of Psychology, 89, 67-71.

Mcclelland, D. C. \& Burnham, D. H. (1976). Power Is the Great Motivator, Harvard Business Review, 54, 100-110. 
Mckenna, D. J. \& Johnson, D. A. (1981). "Selection Risk, Sex-Role Stereotyping and Sex Discrimination in Employment Decision," Journal of Occupational Behaviour, 2, 223- 228.

Pheterson, G. I., Kiesler, S. B. \& Goldberg, P. A. (1971). "Evaluation of the Performance of Women as a Function of Their Sex, Achievement and Personal History," Journal of Personality and Social Psychology, 19, 114-118.

Rosen, B. \& Jerdee, T. H. (1974). "The Influence of Sex-Role Stereotypes on Evaluations of Nmale and Female Supervisory Behaviour," Journal of Applied Psychology, 59, 9-14.

Schein, V. E., Mueller, R. \& Jacobson, C. (1989). "The Relationship Between Sex Role Stereotypes and Requisite Management Characteristics among College Students," Sex Roles, 20(L/2), 103-110.

Schmitt, N. \& Lappin, M. (1980). "Race and Sex as Determinants of the Mean and Variance of Performance Ratings," Journal of Applied Psychology, 65, 428-435.

Shackelford, S., Wood, W. \& Worchel, S. (1996). "Behavioral Styles and the Influence of Women in Mixed-Sex Groups," Social Psychology Quarterly, 59, 284-293.

Terborg, J. R., Peters, L. H., Ilgen, D. R. \& Smith, F. (1977). "Organizational and Personal Correlates of Attitudes Toward Women as Managers," Academy of Management Journal, 20, 89-100.

Wallston, B. S. \& O’leary, V. E. (1981). 'Sex Makes a Difference: Differential Perceptions of Women and Men,' In L. Wheeler (Ed.), Review of Personality and Social Psychology, Vol. 2, Pp. 9-41, Sage, Beverley Hills, Calif.

Wilson, F. M. \& Beaton, D. (1992). 'The Theory and Practice of Appraisal: The Case of a Scottish University,' Paper Presented to British Academy of Management Conference, Bradford, September and Published in Higher Education Quarterly, 47(2), 163-189. 